\begin{tabular}{rr} 
çaḡdaş & Yaratıcı Drama Dergisi 2015, 10(1), 31-38 \\
drama & www.yader.org \\
\hline
\end{tabular}

\title{
Pina Bausch Açısından Dansta Doğaçlama
}

\author{
Bahar Dinçakman ${ }^{1}$
}

\begin{tabular}{|c|c|}
\hline Makale Bilgisi & Öz \\
\hline DOI: $10.21612 /$ yader.2015.003 & Bireyin içinde yaşanan psikolojik, duygusal gerilimlerin, estetik değer taşıyan \\
\hline $\begin{array}{l}\text { Anahtar Sözcükler } \\
\text { Doğaçlama } \\
\text { Drama } \\
\text { Dans } \\
\text { Uzam } \\
\text { Göstergebilim }\end{array}$ & $\begin{array}{l}\text { gövdesel hareketlerin doğaçlama biçimde bütünleştirilmesiyle, fiziksel bir } \\
\text { dışavurum gerçekleşmektedir. Yaratıcılık, hayal gücü ve yaşantıya dayalı } \\
\text { deneyimler, dansla harmanlanarak somutlaşmaktadır. Birey, elindeki kavramı sıkıca } \\
\text { tutarak onu içselleştirerek hareketleri, jest ve mimikleri ile dansında uyumlu bir } \\
\text { bütünlük oluşturmaktadır. Dansta doğaçlamanın Pina filmi (2011) kapsamında } \\
\text { ele alınacağl araştırmada, Pina Bausch'un dans, koreografi, doğaçlama ile ilgili } \\
\text { düşüncelerinin yansıdığl dans görüntülerinin insan, zaman, uzam çerçevesinde } \\
\text { irdelenmesi amaçlanmaktadır. Elde edilen bulgular ışığında "Pina" filminde yer } \\
\text { alan doğaçlama dans figürleri, göstergebilimsel analiz yöntemiyle çözümlenecektir. }\end{array}$ \\
\hline
\end{tabular}

\section{Improvisation in Dance with regard to Pina Bausch}

\begin{tabular}{l} 
Article Info \\
\hline DOI: 10.21612 yader.2015.003 \\
\hline Keywords \\
Improvisation \\
Drama \\
Dance \\
Space \\
Semiotics
\end{tabular}

\begin{abstract}
A physical manifestation takes place by integrating psychological, emotional tensions experienced inside of the individual with bodily movement carrying aesthetic value in an improvisation format. Experiences based on creativity, imagination and life, are embodied by being blended by dance. Individual constitutes an harmonic unity in his/her dance with the motions, gestures, and facial expressions by internalizing the concept and holding it tightly. In the research that the improvisation in dance will be discussed within the scope of Pina film (2011), it is aimed to investigate the dance images reflected Pina Bausch's thoughts about dance, choreography, improvisation in the frame of human, time and space. Improvisation in dance film Pina (2011) As part of the research will be discussed, Pina Bausch's dance, the dance of reflected images of human thinking about, time, aims to examine the space frame. In the light of the findings, improvised dance figures located in "Pina" film will be resolved with the semiotic analysis.
\end{abstract}

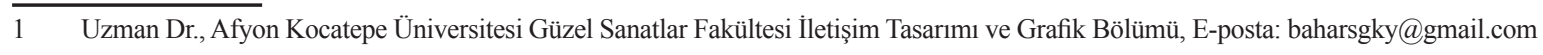




\section{Giriş}

2009 yılında hayatını kaybeden dans sanatçısı ve koreograf Pina Bausch'a övgü niteliğinde çekilen Pina filmi (2011) kapsamında irdelenen dansta doğaçlama, bu çalışmanın konusunu oluşturmaktadır. Dans tiyatrosu akımının öncülerinden biri olan Pina Bausch, Almanya'nın Wuppertal kentindeki Tanztheater Wuppertal Pina Bausch isimli topluluğun sanat yönetmeni ve koreografıdır (http://tr.wikipedia.org/). Çalışma kapsamında incelenen veriler, Pina filminden elde edilen görsel veriler ile Pina Bausch'un ekolünden gelen dans sanatçılarının oluşturdukları performanslardan oluşmaktadır. Çalışmada, Pina Bausch'un dans, koreografi, doğaçlama ile ilgili düşüncelerinin yansıdığı dans görüntülerinin göstergebilimsel analiz yöntemiyle sorgulanarak insan, zaman, uzam çerçevesinde irdelenmesi amaçlanmaktadır. Bu bağlamda çalışma, Pina Bausch ve Pina filmi, dansta doğaçlama başlıklarından oluşan kuramsal çerçeve, Pina filmindeki doğaçlama dans görüntülerinin analizi, yöntem, sonuç ve öneriler kısımlarından oluşmaktadır.

\section{Kuramsal Çerçeve}

\section{Pina Bausch ve Pina Filmi}

Alman koreograf Pina Bausch’a övgü niteliğindeki “Pina” filmi, Pina Bausch’un en ünlü eserlerinin, dansçıları tarafından canlandırılmasıyla oluşturulmuştur. Filmin yönetmeni Wim Wenders'tir (imdb.com). Opera, tiyatro, dans, film ve televizyonlar için set ve kostüm tasarımları yapan Peter Pabst (http://download.theory1.net) Pina Bausch'un eşidir ve onun dans koreografilerinde, set ve kostümleri tasarlamıştır.

Betimleme, tarif edilmiş olanın yetersiz kalıp, boşluğa yuvarlandığı noktada gündeme gelir; ancak burada öngörülen amaca ulaşabilmek için en sıradan şeyleri bile ustaca tarif edebilecek bir yetiye sahip olmak gerekir. Buysa, her ne kadar yetenekle açıklansa da aslında söz konusu sanatçının çoğu kez farkına varmadığı bir dürtüden kaynaklanır (Ergüven, 2006: 84). Pina Bausch ise filmde yer alan kayıtlarında yaratım sürecini şu cümlelerle açıklamaktadır: "Kendi başıma Café Müller'de dans ettim. Hepimiz gözlerimizi kapattı. Tekrar yaptığımız zaman o hissi alamadım. Kafamı kurcalayan bir histi bu. Gözlerim kapaltyken kendimize tepeden bakarken ya da o tarz bir şey yaparken birden, çok büyük bir değişiklik yaratacak bir durumu fark ettim. Tüm bu farka oradaki şey neden olmuştu! Gerçek his bir anda orada ortaya çıkmıştı. Bunun ne kadar hayati bir konu olduğuna inanamazsın. En ufak bir detay bile çok önemlidir. Tüm bunlar bir dili oluşturuyor. Okumasını öğrenebileceğin bir dili..." (Bausch, Pina; 17:45).

Pina filminde yer alan dans figürleri, bireyin yaşantılarından alıntılanan temsil biçimleridir. Bunun yanında Pina'da yer alan dans koreografilerinde, doğadan ve insandan bağımsız biçimde doğada gerçekleşen olaylardan izleri görmek mümkündür. Örneğin filmin giriş sahnesi bu dizelerle başlamaktadır. "Yakında yine ilkbahar gelecek... Çimenler filizlenecek... Sonra yaz gelecek... Uzun çimler... Güneş... Sonra sonbahar gelecek... Düşen yapraklar... Ve sonra da kış... Ilkbahar. Yaz. Sonbahar. Klş”. İlk dans koreografisi dört mevsimi ve mevsimler arası geçişleri simgelemektedir. Lhote'a göre, ideal amaç, varılacak son nokta, henüz keşfedilmeyi beklemektedir (2001, s. 79). Filmin başında ve sonunda dört mevsim dans koreografisinin kullanılması da varılacak son noktanın olmadığını, bireyin ise zamanın ve uzamın devingenliğinde, durmadan, ileriye doğru yol aldığını 
iletmektedir. Pina'da birey, katı bir varlık değildir. Eğilip bükülebilen, şekil değiştiren, yolunu kendi çizen, dış koşullardan bağımsız bir niteliğe sahiptir. Pina'da dans sanatçıları, bunu sözleriyle dile getirmektedir. Ancak daha önemlisi, her sanatçı bunu dans figürleriyle, hareketleriyle, vücut diliyle de ifade edebilmektedir.

\section{Dansta Doğaçlama}

Bireyin içinde yaşanan psikolojik, duygusal gerilimler, içgüdü ve tutkular, "gerçek nesnelerin, hareketlerin ve olayların beden yolu ile temsil edilebilmesi, simgeleştirilmesi (Önder, 1999, s.133) ile ilintilidir. Bu bağlamda doğaçlama, bir ön hazırlık yapmadan bir form üstüne çalışmak ve sanatsal ifadeyi ona dayanarak yaratmak olarak da algılanmaktadır. Bu türden bir algı, müzik doğaçlamalarında, dans doğaçlamalarında ve sahne doğaçlamalarında görülmektedir (Çevik, 2008, s. 38). Ergüven'e göre yeni bir şey düşünebilmenin temel koşulu görmektir; çünkü sahne dilinde farklıyı tasarlamış olmanın hiçbir kanıtı yoktur. Gözün yorgun düştüğü bir yerde muhakeme yeteneği de sendelemeye başlamıştır (2007, s. 74). Modern özne anlayışının (Işık, 1998, s.153), dans ve doğaçlama ile yeniden sunumu bir çeşit eylem niteliği taşımaktadır. Bir olguya, nesneye ve duruma olağanın dışında bakmak, yeni bir yorumu ve eleştirel bakış açısını beraberinde getirmektedir. Doğaçlama dans, bu bakımdan toplumsal bir durumu eleştiri niteliği de taşıyabilir; içinden çıkılamayan tarifi kelimelerle zor ifade edilebilecek soyut bir durumu beden dili ve dans yoluyla somutlaştırma eylemi olarak da ortaya çıkabilir.

Dramada ve dansta; paylaşım, grupla iletişim kurma, grupla etkileşimi sağlama amaçları bulunmaktadır. Ayrıca bireysel dışavurum da söz konusudur. "Drama, grubu ve kendini, gruptaki yaşantılar aracılığ 1 ile araştırmayı, incelemeyi sağlar" (Önder, 1999, s. 75). Oyun yeteneği düş gücü ile gelişir. Yaşam boyu yapılan, düşlenen, söylenen her şeyde oyunsu öğeler vardır (Üstündağ, 2004, s. 32). Sanatın sosyo-kültürel yönünün izleyiciye aktarılmasında, dramanın ve doğaçlama dansın da rolü vardır. "Sanat, taşlaşmış dünyayı konuşturarak, ona şarkı söyleterek, belki de ona dans ettirerek şeyleşme ile savaşır. Geçmiş acıyı ve geçmiş sevinci unutmak, baskıcı bir olgusallık ilkesi altındaki yaşamı hafifletir. Karşıt olarak anımsama, acının yenilmesi ve sevincin sürekliliği için itkiyi kışkırtır. Ama anımsamanın gücü, düş kırıklı̆̆ına uğratılır; sevincin kendisi acı tarafindan gölgelenir. Kaçınılmaz olarak mı? Tarihin çevreni henüz açıktır. Ĕger geçmişşeylerin anısı, dünyayı değiştirmek için savaşımda güdüleyici bir güç olacaksa, savaşım önceki tarihsel devrimlerde şimdiye dek bastırılmış bir devrim uğruna verilecektir” (Marcuse, 1997, s. 62).

Çevik (2006, s. 17), "gözleme yönelik seçilmiş alıştırmaların yanında doğaçlamaya dayanan çalışmaların yapılmasının oyuncu adayının bu konuda kendini geliştirmesine katkıda bulunacağını" savunmaktadır. Ona göre, “oyuncunun gözlem yeteneğini geliştirmeye destek olacak birçok doğaçlama yapılabilir ve bunlar oyuncuda bu yetinin gelişmesini destekler" (Çevik, 2006, s. 17). Benzer biçimde Önder (1999, s.118) dramayla ilgili olarak "Yaşanılan yaşantıların derlenip toparlanması, düşüncelerin, bilgilerin tasnif edilmesi, böylece üzerinde çalışılan kavramların, davranışların, konuların tekrar tanımlanması, vurgulanması olanağı yaratılmış olur.” ifadesini kullanmaktadır. Drama ve dansın doğaçlanmasında, pratikte ortak birçok noktasının var olduğu görülmektedir. Doğaçlama dans, anlık oluşum gibi görünse de temelinde gözleme dayalı bir süreç yatmaktadır. Kendisini yeterince tanımlamamış ya da çözümlememiş birey, psikolojik gerilimlerinin 
doğaçlamayla sunumunda tıkanıklık yaşayabilir. Benzer biçimde, toplumsal olguları, durumları, problemleri veya pozitif yanları gözlemlemeden belirlenen konuda, bir doğaçlama drama etkinliğinin gerçekleşmesi mümkün olmayacaktır.

Işık (1998, s.154), bireyin homo-dubleks yani Kartezyen anlayışın ikiye ayırdığı ruh ve bedenin toplamından daha fazlası olduğunu; homo-kompleks olduğunu savunmaktadır. Bu çerçevede toplumsal eylemin öznelerinin birer robot olmadıklarını, onların dışarıdan verilmiş bir ruh ya da akılla eyleyen aktörlerden daha fazla bir şey olduklarını dile getirmektedir. Burada, doğaçlama dansın topluma ve bireye eleştirel bakma aracı olma özelliği ön plana çıkmaktadır. Beden, bir çeşit eylem aracı olarak psikolojik, duygusal ve fiziksel dişavurumu gerçekleştirendir.

"Yorum, sınırları önceden çizilmiş olan bir devinim alanındaki özgürlük değil, bizi bugün ilgilendiren bir şeyi bulup çıkarmaktır" (Ergüven, 2007, s. 75). Pina'da doğaçlama dans figürlerinin yanında söze dayalı güçlü ifadelerin olduğu da görülmektedir. Örneğin bireyin farkındalığı şu dizelerle dişavurulmaktadır: "Ben gencim... Kulaklarım amacımı duyuyor... Aklım, gücümdür... Gözlerim rüyaları görür... Düşüncelerim gelişmiştir... Ve bedenim kuvvetlidir”. Işık (1998, s.107)'a göre, "Beden Hristiyanlıkta olduğu gibi, kapitalizmde de hem sevilir hem reddedilir. Beden bir yandan aşağılanırken öte yandan nesneleşmiş, yasaklanmış yabancılaşmış şey olarak arzulanır. Beden ruhun-kültürün içinde, doğanın kültürün içinde olduğu gibi, kontrolünün mümkün olduğu kanısı hem Hristiyanlık hem de kapitalizmde temel anlayıştır. Adorno ve Horkheimer'a göre insanlar, bedenlerinden kaçamazlar ve onu yok edemediklerinden onun emirlerine uyarlar" (1998, s. 107). Oysa beden, dansta özgür bir araçtır. Düşünce, duygu, olay, durum anlatımında sözlerin askıya alınmasıyla bedenin işe koşulmasıyla ortaya çıkan görüntüler, izleyiciyi göstergeler yoluyla düşünmeye itmektedir. Görme ve duyma aracılığıyla müzik, dans ve kompozisyon düzenlemeleriyle oluşturulan zıtlık veya uyum aracılığıyla duygular, psikolojik durumlar, değişimler, iç içe birbiriyle ilişkilendirilerek verilmektedir. Strauss'un da Mit ve Anlam'da dediği gibi "Farklılıklar fazlasıyla verimlidir. İlerleme ancak farkl11ıklarla olmuştur" (1986, s. 30). Pina'da da bireysel farkl1lıklara, değişimin/dönüşümün doğaçlama dans aracılığıyla ifade edilmesine tanık olunmaktadır.

\section{Pina Filmindeki Doğaçlama Dans Görüntülerinin Analizi}

Pina, kendisini ve çalışmalarını tanımladığı "What moves me?" (Beni ne harekete geçirir?) yazısında, set tasarımcısı Peter Pabst'la 27 yılı aşkın süredir çalıştığını ve her defasında yeni, var olmayanı denediklerini dile getirmektedir. Pina filminde de dansçıları, pek çok konuda olduğu gibi Pina'nın bu görüşüne de sadık kalarak dans koreografilerini birbirinden farklı ortamlarda gerçekleştirmektedir. 
Resim 1. Pina filminden bir sahne

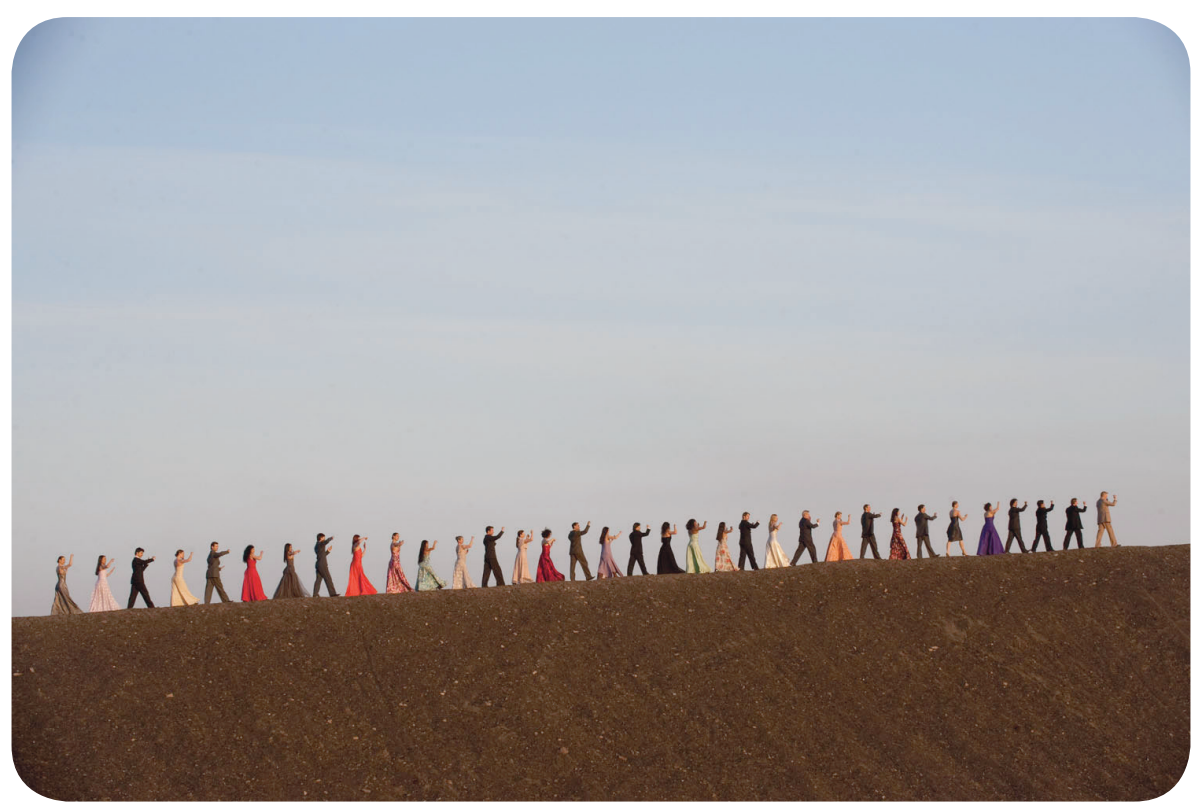

Tablo 1. Pina filmi sahnesi için göstergebilimsel analiz

\begin{tabular}{|l|l|l|l|}
\hline \multicolumn{1}{|c|}{ Gösterge } & \multicolumn{1}{|c|}{ İnsan } & \multicolumn{1}{c|}{ Uzam } & \multicolumn{1}{c|}{ Konu ve Zaman } \\
\hline Gösteren & $\begin{array}{l}\text { Birbirinin ardı sıra } \\
\text { dizilmiş kadın ve erkek } \\
\text { dansçlar }\end{array}$ & $\begin{array}{l}\text { Doğa, tepe, toprak, } \\
\text { gökyüzü }\end{array}$ & $\begin{array}{l}\text { Gün batımı, dört mevsimi } \\
\text { betimleyen dans koreografisi }\end{array}$ \\
\hline Gösterilen & $\begin{array}{l}\text { Kadın ve erkeklerden } \\
\text { oluşan uyumlu bir dans } \\
\text { grubu }\end{array}$ & $\begin{array}{l}\text { Doğanın ortasında } \\
\text { gerçek ortamında } \\
\text { gerçekleştirilen } \\
\text { dans }\end{array}$ & $\begin{array}{l}\text { Filmin başında ve sonunda } \\
\text { dört mevsimi tanımlayan dans } \\
\text { koreografisinin yer alması, } \\
\text { zamanın döngüselliğini ifade } \\
\text { etmektedir. }\end{array}$ \\
\hline
\end{tabular}

Resim 2. Pina filminden bir sahne
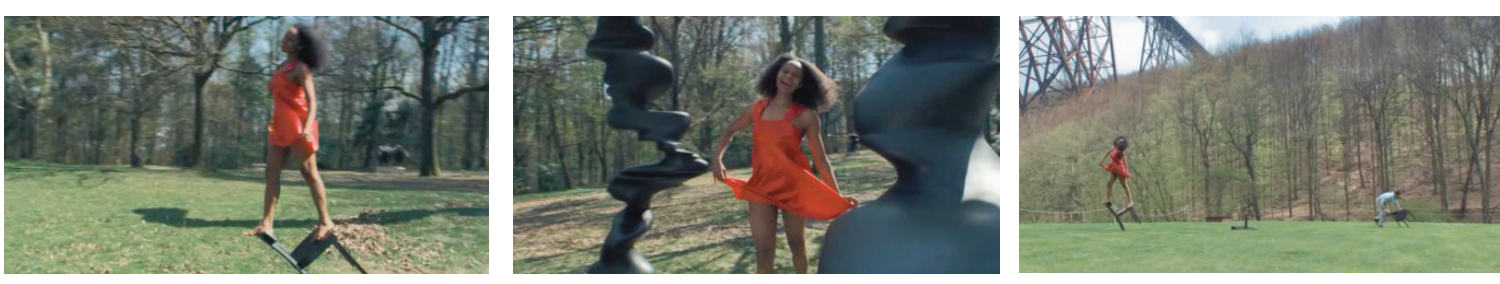

Tablo 2. Pina filmi sahnesi için göstergebilimsel analiz

\begin{tabular}{|c|l|l|l|}
\hline Gösterge & \multicolumn{1}{|c|}{ İnsan } & \multicolumn{1}{c|}{ Uzam } & \multicolumn{1}{c|}{ Konu ve Zaman } \\
\hline Gösteren & $\begin{array}{l}\text { Kırmızı elbiseli kadın ve } \\
\text { sandalyeleri düzenleyen erkek }\end{array}$ & $\begin{array}{l}\text { Doğa, ağaçlar ve çim } \\
\text { alan, sandalyeler, heykel }\end{array}$ & Pina’nın ölümü \\
\hline Gösterilen & $\begin{array}{l}\text { Ölüm sonrası özgürleşme, } \\
\text { hafifleme }\end{array}$ & $\begin{array}{l}\text { Ölümün aydınlığı, } \\
\text { duygunun hafifliği }\end{array}$ & $\begin{array}{l}\text { Pina’nın ölümüne } \\
\text { adanmış dans } \\
\text { koreografisi }\end{array}$ \\
\hline
\end{tabular}


"Pina, sürpriz bir şekilde bizi çok erken terk etti. Düşünüyorum da sonuç olarak her şeyi ardında bırakmıştı ve artık özgürdü. Bu nedenle ona bu anın aydınlığını ve bu duygunun hafifliğini vermek istedim”. Pina'nın ölümüne adanmış koreografiyi tasarlayan ve performansa dönüştüren dans sanatçısının sözlerinden anlaşıldığı gibi Pina'nın dansçıları, ölümün verdiği hüznü ironik bir biçimde değiştirerek Pina'nın ölümünü hafiflik, rahatlama, özgürleşme olarak yorumlamayı tercih etmiştir.

\section{Resim 3. Pina filminden bir sahne}

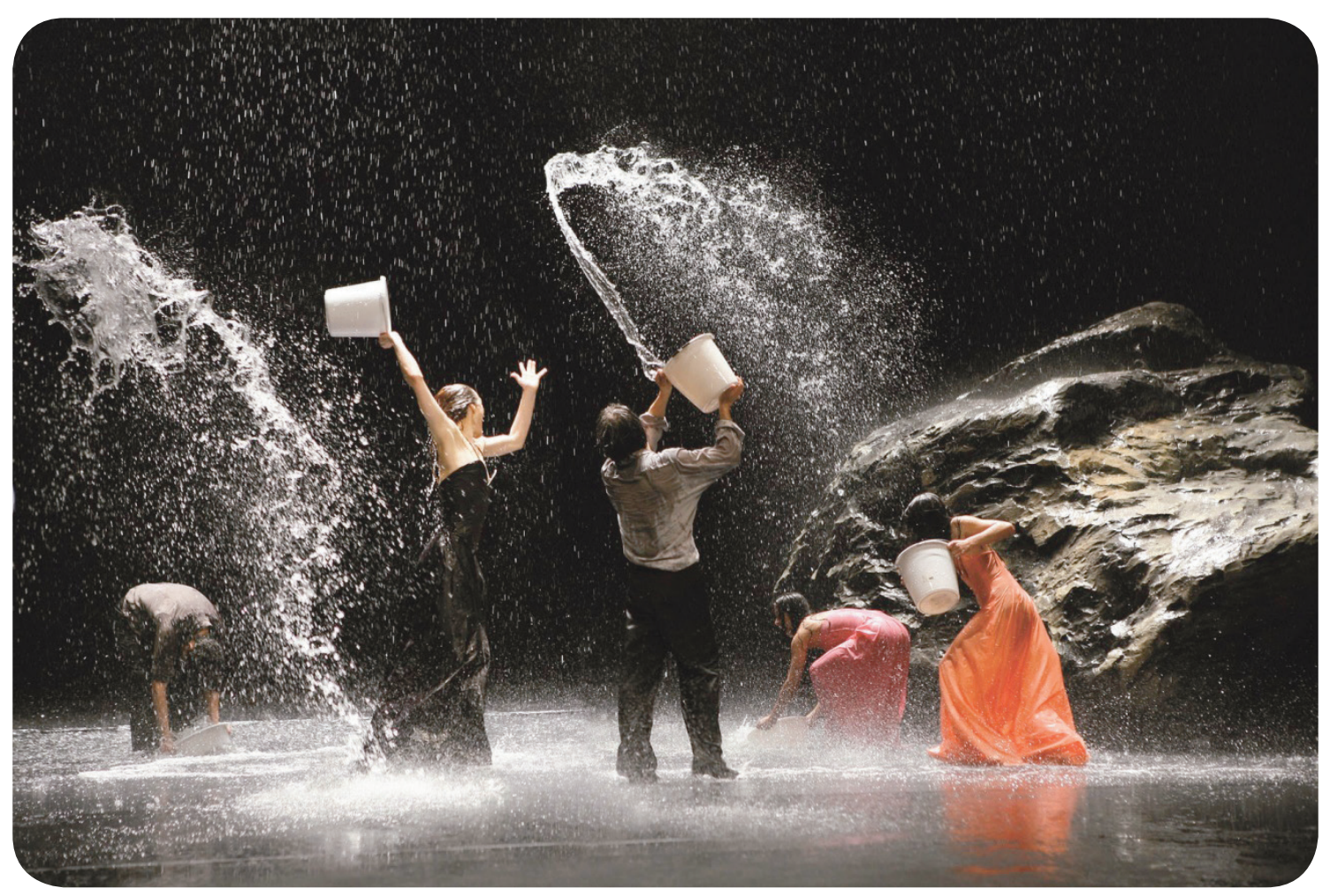

Tablo 3. Pina filmi sahnesi için göstergebilimsel analiz

\begin{tabular}{|c|l|l|l|}
\hline Gösterge & \multicolumn{1}{|c|}{ İnsan } & \multicolumn{1}{c|}{ Uzam } & \multicolumn{1}{c|}{ Konu ve Zaman } \\
\hline Gösteren & $\begin{array}{l}\text { Yağmurun altında 1slanan ve } \\
\text { dans eden insanlar }\end{array}$ & $\begin{array}{l}\text { Sahne (siyah tonlarda), } \\
\text { yağmur, kaya parças1, su } \\
\text { birikintisi, yağmur }\end{array}$ & $\begin{array}{l}\text { Yağmurla birlikte } \\
\text { suyun yansıtıcı gücü, } \\
\text { sıçramalar, sesler }\end{array}$ \\
\hline Gösterilen & $\begin{array}{l}\text { Suyla özgürleşme, hafifleme, } \\
\text { enerji ile oluşan uyum, } \\
\text { biraradalık }\end{array}$ & $\begin{array}{l}\text { Dans sahnesinin suyla } \\
\text { birlikte sıra dışı biçimde } \\
\text { sahnelenişi }\end{array}$ & $\begin{array}{l}\text { Ölüm sonrasıyla } \\
\text { ilişkilendirilmiş dans } \\
\text { koreografisi }\end{array}$ \\
\hline
\end{tabular}

\section{Yöntem}

Doğaçlama dans figürlerinin oluşum süreçleri ve bu dans figürlerinin oluşum sürecinde sanatçıların yönlerini bulmalarında Pina Bausch'un katkısı, Pina filminin önemini oluşturmaktadır. Filmden elde edilen görsel veriler, dansta doğaçlama konusu kapsamında göstergebilimsel yöntemle incelenmiştir. Bireyin yaşantısal deneyimlerinin yansıdığı bu dans imgeleri, bireyin ifade biçimi olarak ve drama ile ilişkilendirilerek irdelenmiştir. 


\section{Araştırmanın Modeli}

$\mathrm{Bu}$ araştırmanın yürütülmesi aşamasında nitel ve betimsel araştırma yöntemi kullanılmıştır. 2011 yılında çekilen Pina filminden elde edilen dans görüntüleri, drama ve dansta doğaçlama ile ilişkilendirilerek göstergebilimsel yöntemle incelenmiştir.

\section{Veri Toplama Araçları}

Pina filminden elde edilen dans görüntüleri, bu araştırmanın verilerini oluşturmaktadır. Araştırma, Pina filmi ve doğaçlama dans figürlerin yer aldığı görsel veriler ile sınırlandırılmıştır.

Araştırmada kullanılan görsel veriler, Pina filminden elde edilerek araştırma kapsamında yer almıştır.

\section{Verilerin Toplanması}

Araştırma, bilgisayar donanımları (bilgisayar, internet ortamı), yazılımları (Adobe Photoshop CS6, Microsoft Word), ilgili literatür olanakları ile sağlanmıştır. Ayrıca araştırmada kullanılan veri toplama araçları, kaynak kitaplar, tezler, süreli yayın ve makalelerin yanında, konu örneklemi üzerinde çalışmak ve görsel veri elde etmek için incelenen Pina (2011) filmidir.

\section{Verilerin Çözümlenmesi}

Araştırmada sonuca ulaşmak için, Pina filminde yer alan doğaçlama dans figürleri göstergebilimsel olarak incelenmiş ve bu incelemelerden yola çıkılarak çözümleme yapılmıştır.

\section{Bulgular}

Pina filminde yer alan doğaçlama dans görüntüleri, kurgulanmış bir bütünlükte izleyiciye sunulmuştur. Pina Bausch'un ekolünden gelen sanatçılar, filmde Pina'nın daha önce sunduğu dans koreografilerini ve kendi dans figürlerini sunmuşlardır.

Soyut kavramları duygusal ve içsel yönleriyle bütünleştirerek dans figürlerinde sunan sanatçılar, bu figürlerin doğaçlandığı anları film boyunca izleyiciyle paylaşmıştır. Dans figürlerinin göstergebilimsel analizlerinde, insan, ortam ve konu bakımından gösteren ve gösterilen irdelenmiştir. Çalışma kapsamında sanatçının doğaçlama dansı gerçekleştirdiği estetik ifade gücünün yanında, uzam ve zaman boyutunun da önem taşıdığı görülmüştür.

\section{Sonuç ve Öneriler}

Pina Bausch, dans tiyatrosunda doğaçlama dansı, duyguların engelsiz ve özgür biçimde ifade edilmesini savunan bir dans sanatçısı ve koreograf olarak çalışmalarında ve deneysel uzam tasarımlarında genellikle doğadan esinlenmiştir. Çalışma kapsamında irdelenen Pina filminde, dans sanatçılarının koreografilerinde, doğadan esinlenmenin ve performanslarını gerçekleştirdikleri uzamların doğanın izlerini taşıdı̆̆ı, hatta bazı performansların bizzat doğanın, kentin içinde gerçekleştiği görülmüştür. Pina'yla yıllarca çalışmış dans sanatçıları, kendilerini ve içsel zenginliklerini en güzel ifade ettikleri koreografilerini bulmalarında Pina'nın katkısını dile getirmişlerdir.

Çalışma kapsamında Pina filminden çıkışla elde edilen bulgular ışığında, dansta doğaçlamanın bireyin psikolojik ve duygusal yanını, fiziksel özelliklerini kullanarak somutlaştırmasının ve izleyiciye yansıtmasının mümkün olduğu görülmüştür. Pina filminde yer alan dans figürlerinin taşıdığ 1 göstergeler, birbirinden farklı duygusal ifadelerin somutlaşmış biçimidir. Pina Bausch’un 
hayatı boyunca çalışmalarında önemsediği sunuş biçimlerinin ve onun kendine özgü dans koreografilerinin de tekrardan performans olarak sunulmasında, özellikle görsel ifadenin yanında uzam ve ses unsurlarına da önem verilmiştir.

Pina filminde yer alan farklı dans koreografilerin doğaçlama dans kapsamında göstergebilimsel analiz yöntemiyle irdelenmesi sonucunda, psikolojik ve duygusal yönlerin ifade aracı olarak vücudun estetik biçimde kullanılmasının yanında; uzam (sahne, yol, metro, orman, vb.) ve zamanın da (ölüm sonrası, ayın hareketleri, yağmur yağış süreci vb.) ifade biçimine katkı sağladığı görülmüştür.

\section{Kaynakça}

Çevik, K. (2006). Kendinden başka birini oynamayı öğrenme sürecinde sanatsal bir araç olarak doğaçlama. Tiyatro Araştırmaları Dergisi, 22.

http://dergiler.ankara.edu.tr/dergiler/13/194/1534.pdf (Erişim tarihi 30.03.2015)

Çevik, K. (2008). Tiyatroda yeni eğilimler: Doğaçlama tiyatro. Tiyatro Araştırmaları Dergisi, 25.

http://dergiler.ankara.edu.tr/dergiler/13/980/12004.pdf (Erişim tarihi 30.03.2015)

Ergüven, M. (2006). Aydinlıkta görmek. İstanbul: Agora.

Ergüven, M. (2007). Strdaş görüntüler. İstanbul: Agora.

Işık, E. (1998). Beden ve toplum kuramı. İstanbul: Bağlam.

Lhote, A. (2001). Sanatta değişmeyen plastik değerler (K. Özsezgin, Çev.). İstanbul: İmge.

Marcuse, H. (1997). Estetik boyut sanatın sürekliliği: Marxist estetiğin bir eleştirisine doğru (Aziz Yardımlı, Çev.). İstanbul: İdea.

Önder, A. (1999). Yaşayarak öğrenme için eğitici drama. İstanbul: Epsilon.

Strauss, C. L. (1986). Mit ve anlam. İstanbul: Alan.

Üstündağ, T. (2004). Yaratıcı drama öğretmenimin günlüğü. Ankara: Pegem.

http://tr.wikipedia.org/wiki/Pina_Bausch (Erişim tarihi 02.02.2015)

http://download.theory1.net/download.php?id=28394 (29.03.2015)

What moves me, http://www.inamori-f.or.jp/laureates/k23_c_pina/img/lct_e.pdf (Erişim tarihi 29.03.2015) http://tr.wikipedia.org/wiki/Pina_Bausch (Erişim tarihi 29.03.2015) 